\title{
High-temperature MEMS Heater Platforms: Long-term Performance of Metal and Semiconductor Heater Materials
}

\author{
Jan Spannhake ${ }^{1, *}$, Olaf Schulz ${ }^{1}$, Andreas Helwig ${ }^{1}$, Angelika Krenkow ${ }^{1}$, Gerhard Müller ${ }^{1}$ and \\ Theodor Doll ${ }^{2}$ \\ ${ }^{1}$ Corporate Research Centre, EADS Deutschland GmbH, D-81663 München, Germany \\ ${ }^{2}$ Institute of Microtechnology Mainz, D-55129 Mainz, Germany \\ * Author to whom correspondence should be addressed. Email: Jan.Spannhake@eads.net
}

Received: 12 July 2005 / Accepted: 24 March 2006 / Published: 7 April 2006

\begin{abstract}
Micromachined thermal heater platforms offer low electrical power consumption and high modulation speed, i.e. properties which are advantageous for realizing nondispersive infrared (NDIR) gas- and liquid monitoring systems. In this paper, we report on investigations on silicon-on-insulator (SOI) based infrared (IR) emitter devices heated by employing different kinds of metallic and semiconductor heater materials. Our results clearly reveal the superior high-temperature performance of semiconductor over metallic heater materials. Long-term stable emitter operation in the vicinity of $1300 \mathrm{~K}$ could be attained using heavily antimony-doped tin dioxide $\left(\mathrm{SnO}_{2}\right.$ :Sb) heater elements.
\end{abstract}

Keywords: Hotplate, heater metallisation, high-temperature stability, electro-migration, doped silicon, doped metal oxide, antimony doped tin oxide. 


\section{Introduction}

Silicon micro-heaters have been a subject of intense research within the past decade. So far the interest in such devices was largely driven by the request for low-heating-power supports for gassensitive metal oxide materials. Moreover, the small thermal inertia of micromachined heater devices allows triggering rapid temperature changes which has opened up new perspectives for developing non-stationary methods of sensor operation [1-4].

As detailed in previous reviews of this subject [5-7] micro heater elements can be realised following two basic architectural designs: (i) closed dielectric membrane and (ii) hotplate devices. The architectural simplicity of the first kind of device is basically enabled by the low heat conductivity of $\mathrm{SiO}_{2}$ and $\mathrm{Si}_{3} \mathrm{~N}_{4}$, which form the structural membrane materials there. In the latter kind of devices semiconductor materials such as silicon (Si) or silicon carbide (SiC) are used as structural membrane materials. Due to the much higher thermal conductivities of these latter materials, closed-membrane architectures are no longer possible and hotplate designs need to be introduced to reduce the heat flow from the heated hotplate to the supporting silicon rim. Using this latter approach, relatively sophisticated devices have been realised in the meantime, co-integrating sensitive materials, bulk Si heaters and electronic read-out chips at the same time [8-9]. Recently, also gas-sensitive field-effect devices have been successfully integrated into such devices [10]. Meeting the relatively modest hightemperature requirements of such gas-sensing devices platinum $(\mathrm{Pt})$ and polycrystalline silicon (poly$\mathrm{Si}$ ) have found wide-spread acceptance as electrically conductive heater materials [11-12].

Building on this work, attempts have been made to introduce novel materials into the micro heater design that allow attaining much higher temperatures in the range of $1300 \mathrm{~K}$ or above. Examples are $\mathrm{SiC}$ membranes and $\mathrm{HfB}_{2}$ heaters [13]. Attaining temperatures in this range, novel applications of micro heater devices become feasible such as thermal IR emitters [14-16], flameless ionisation detectors [17] and surface ionisation devices [18]. In the present paper, we expand on this subject, reporting on the high-temperature-stability of silicon-on-insulator (SOI) based thermal IR emitters, which have been heated using different heater materials and heater designs. In particular, we compare the performance of metal $(\mathrm{Pt}, \mathrm{PtSi})$ and semiconductor heater materials $\left(\mathrm{Si}: \mathrm{B}\right.$ and $\left.\mathrm{SnO}_{2}: \mathrm{Sb}\right)$ to point out that semiconductor heaters provide a significantly better performance at operation temperatures in the $1300 \mathrm{~K}$ range.

\section{Emitter design}

For reasons of attaining a low power consumption and short thermal response time, thermal IR emitter devices should be based on micro-machined membrane structures. For reasons of hightemperature compatibility the membrane should further consist of materials capable of operating at temperatures up to $1300 \mathrm{~K}$ for prolonged periods of time.

Suitable materials in this respect are mono-crystalline silicon (Si) or silicon carbide (SiC) [19-29]. In ambient atmosphere both materials tend to form a natural oxide whose growth is diffusioncontrolled and thus self-limiting. $\mathrm{SiC}$ in this context has an advantage, as oxidation rates are smaller than the Si-ones by a factor of 5 to 10 in the relevant temperature range [21-22]. 
Both materials have a high thermal conductivity [23-24], which supports short thermal response times and thus a high modulation depth when operated in a discontinuous AC mode. High thermal conductivity, however, is not compatible with low electrical power consumption. For this latter reason, closed membrane designs cannot be used; hotplate structures rather need to be introduced to limit the cross sectional area of the heat conduction paths from the heated hotplate towards the supporting silicon substrate (Fig. 1).
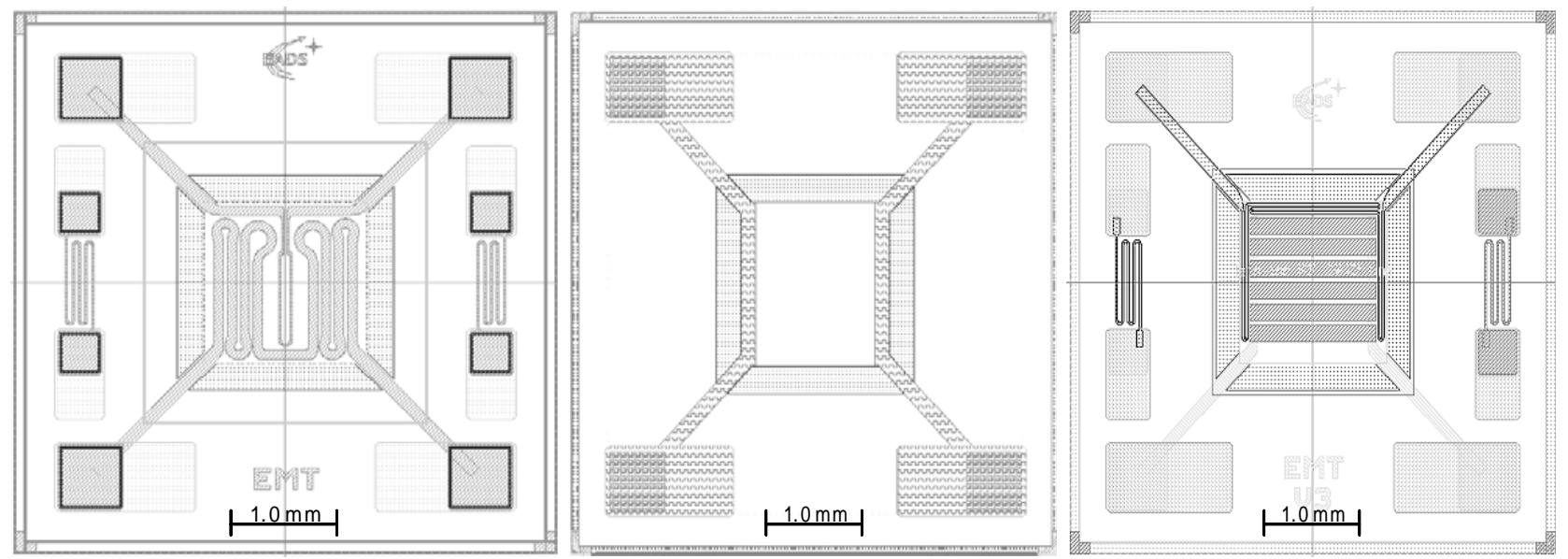

Figure 1. EM1 (left) mask layout of thermal IR emitter chips with on-chip temperature sensing elements for controlling the membrane temperature $T_{\text {mem }}$ and for assessing the long-term drift of the heater meanders [25]. EM2 (middle) is a design, which uses the thin, highly doped Si membrane in the middle as a bulk heater element with lateral Pt contact structures. EM3 (right) emitter design featuring an area heater based on $\mathrm{SnO}_{2}$ : $\mathrm{Sb}$ contacted by lateral $\mathrm{Pt}$ metallisations and additional on-chip temperature sensing elements for controlling the membrane temperature $T_{\text {mem }}$.

It needs to be kept in mind that not only the membrane itself has to withstand the high operation temperatures, but also the heater and temperature sensor metallisation on top of the membrane structure. Here, platinum and highly doped tin dioxide $\left(\mathrm{SnO}_{2}: \mathrm{Sb}\right)$ have been closely investigated. Platinum as a noble metal exhibits a high melting temperature and a low oxidation rate at elevated temperatures. At the same time, it possesses a low specific resistance and a positive temperature coefficient, which is attractive for temperature sensing and temperature control purposes. When directly deposited on Si the evaporated Pt layer is also able to form a platinum silicide (PtSi) layer by interdiffusion and reaction with the substrate, a property which is attractive for providing an improved film adherence. Tin dioxide $\left(\mathrm{SnO}_{2}\right)$, on the other hand, is a widely used metal oxide semiconductor, featuring a very high melting point and a negligibly small oxidation rate at elevated temperatures, as it is already in a fully oxidised state. Its specific resistance is intrinsically very high but can be reduced by adding substitutional dopants such as antimony (Sb). Its temperature coefficient of resistivity is in principle negative but may attain positive values in the case of heavy doping. In Table 1 the most relevant properties of the materials employed are listed. 
Table 1. Properties of materials used for the emitter design [21-24,26].

\begin{tabular}{|l|l|l|l|l||}
\hline \hline Material & $\begin{array}{l}\text { Melting } \\
\text { point } \\
{[\mathrm{K}]}\end{array}$ & $\begin{array}{l}\text { Oxidation } \\
\text { rate } \\
{[\AA / \text { sec at } 1273 \mathrm{~K}]}\end{array}$ & $\begin{array}{l}\text { Specific } \\
\text { Resistance } \\
{[\Omega \cdot \mathrm{cm} \text { at } 300 \mathrm{~K}]}\end{array}$ & $\begin{array}{l}\text { Expansion } \\
\text { coefficient } \\
{[\mathrm{ppm} / \mathrm{K}]}\end{array}$ \\
\hline $\mathrm{Si}$ & 1688 & 4 & $2.3 \cdot 10^{5}$ & 2.6 \\
\hline $\mathrm{Si}: \mathrm{B}$ & 1688 & 4 & $5 \cdot 10^{-3}$ & 2.6 \\
\hline $\mathrm{SiO}_{2}$ & 1986 & 0.4 & $1 \cdot 10^{14}$ & 0.5 \\
\hline $\mathrm{SiC}$ & 3073 & - & $2 \cdot 10^{3}-100$ & 6 \\
\hline $\mathrm{SnO}_{2}: \mathrm{Sb}$ & 2193 & $<0.1$ & $10-4 \cdot 10^{-3}$ & 1 \\
\hline $\mathrm{Pt}$ & 2042 & & $1.1 \cdot 10^{-5}$ & 9 \\
\hline \hline
\end{tabular}

\section{Fabrication}

In realizing the emitter designs shown in Fig. 1, silicon-on-insulator (SOI) wafers with an overall thickness of $356 \mu \mathrm{m}$ and a top silicon layer thickness of $6 \mu \mathrm{m}$ were used as substrate materials. In order to allow the top silicon layer to be used as an active heater material itself, this top layer was heavily boron doped (Si:B; $\mathrm{C}_{\mathrm{B}} \sim 10^{20} \mathrm{~cm}^{-3} ; \rho \sim 5 \times 10^{-3} \Omega \mathrm{cm}$ ). As previously reported [27], the main advantage of using SOI wafers is the simplicity of the device processing and the ease of obtaining monocrystalline silicon membranes with a reproducible thickness, which corresponds to the top silicon layer thickness of $6 \mu \mathrm{m}[4]$.

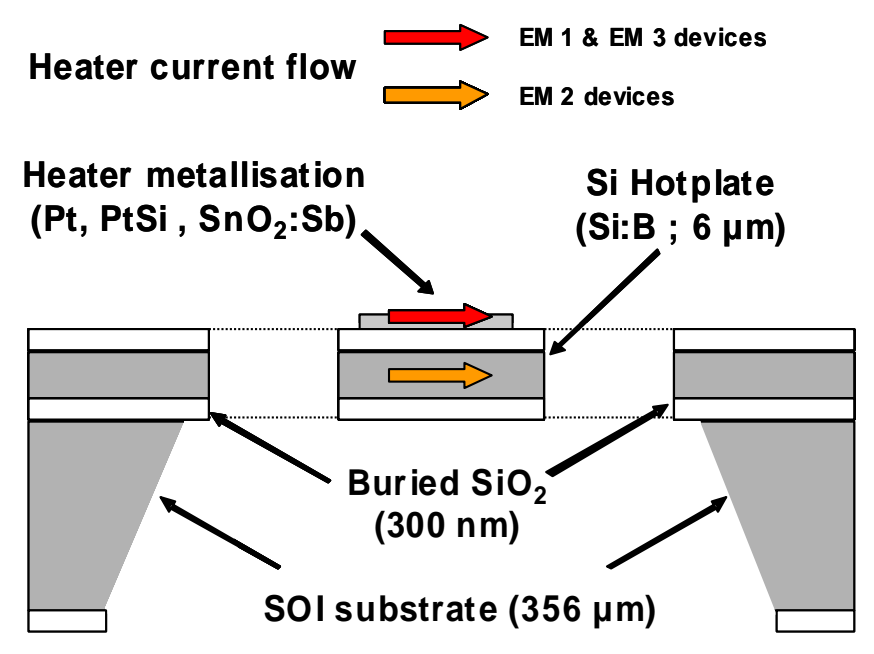

Figure 2. Cross section through the emitter devices exhibiting an etch trough and a spider-like hotplate structure for thermal insulation. The electrical isolation of hotplate and heater is assured by a $700 \mathrm{~nm}$ thick layer of $\mathrm{SiO}_{2}$ on top of the $\mathrm{Si}: \mathrm{B}$ membrane. Arrows indicate the positioning of the heater current flow in the individual designs.

The first processing step of the above devices consists in the growth of a $700 \mathrm{~nm}$ thick oxide on both surfaces of the SOI wafers. In this way a high-quality insulation is formed that separates the thinfilm metallisation on the front side from the top Si:B layer which will ultimately form the suspended membrane structure. In case the top $\mathrm{Si}$ : $\mathrm{B}$ layer is used as a bulk heater material itself, this surface 
oxide serves as a passivation against further rapid oxide growth. In a later process stage, the two surface oxides are additionally used as etch masks for the Si membrane formation (backside) and the hotplate definition (front side). In the second step, the heater and temperature sensor metallisations are carried out on the front surface and heater meanders, temperature sensing and reference resistors are structured. For this purpose, thin layers of metals or metal oxides have been deposited using standard vapour deposition techniques. The degenerately doped $\mathrm{SnO}_{2}$ : Sb layers, for instance, were obtained by e-beam evaporation of mixtures of $\mathrm{SnO}_{2}$ and Sb powders followed by a subsequent annealing step in air at $1320 \mathrm{~K}$ for 2 hours.

During this latter annealing step the deposited amorphous $\mathrm{SnO}_{2}: \mathrm{Sb}$ changes to a rutile structure which causes the incorporated Sb atoms to become incorporated as substitutional dopants [28-29]. The average thickness of the deposited layers of $\mathrm{SnO}_{2}$ : $\mathrm{Sb}$ was about $900 \mathrm{~nm}$. A maximum conductivity in fully annealed films of about $4500 \mu \Omega \mathrm{cm}$ was obtained by employing Sb admixtures on the order of $5 \%$ by weight. The structuring of such layers was performed by lift-off prior to the $\mathrm{SnO}_{2}$ :Sb annealing step using a pre-patterned mask of photo resist. This simple method of structuring $\mathrm{SnO}_{2}: \mathrm{Sb}$ layers is enabled by the fact that $\mathrm{SnO}_{2}: \mathrm{Sb}$ can be deposited at room temperature with the high-temperature dopant activation step following afterwards.

Pt layers were deposited by electron beam evaporation and structured using wet etching in aqua regia and photo resist masks. For improving the adhesive properties of the Pt films, additional annealing steps at temperatures of about $1000 \mathrm{~K}$ had been applied.

Following the completion of the metallisation steps, membranes were realized using an anisotropic wet etching process of silicon to open the membrane window on the backside of the SOI wafer. Subsequently, the buried silicon dioxide of the SOI wafers was removed in an additional wet etching process. Finally, the hotplate was realized by performing a dry etching process from the front side to create the suspended membrane structures displayed in Figs. 2 and 3. The geometrical parameters of the fabricated emitters are listed in Table 2.

Table 2: Geometrical hotplate design parameters.

\begin{tabular}{|l|l|}
\hline Outer chip dimension & $5000 \mu \mathrm{m}$ \\
\hline Outer membrane dimension & $2000 \mu \mathrm{m}$ \\
\hline Membrane size & $1500 \mu \mathrm{m}$ \\
\hline Length of Si suspensions & $350 \mu \mathrm{m}$ \\
\hline Width of Si suspensions & $150 \mu \mathrm{m}$ \\
\hline Thickness of Membrane and Si suspensions & $6 \mu \mathrm{m}$ \\
\hline Pt heater meander (length x width x thickness) & $12000 \mu \mathrm{m}$ x $100 \mu \mathrm{m}$ x $0.4 \mu \mathrm{m}$ \\
\hline $\mathrm{SnO}_{2}$ :Sb heater (EM3) & $6 \mathrm{x} 2000 \mu \mathrm{m}$ x $250 \mu \mathrm{m}$ x $0.95 \mu \mathrm{m}$ \\
\hline
\end{tabular}



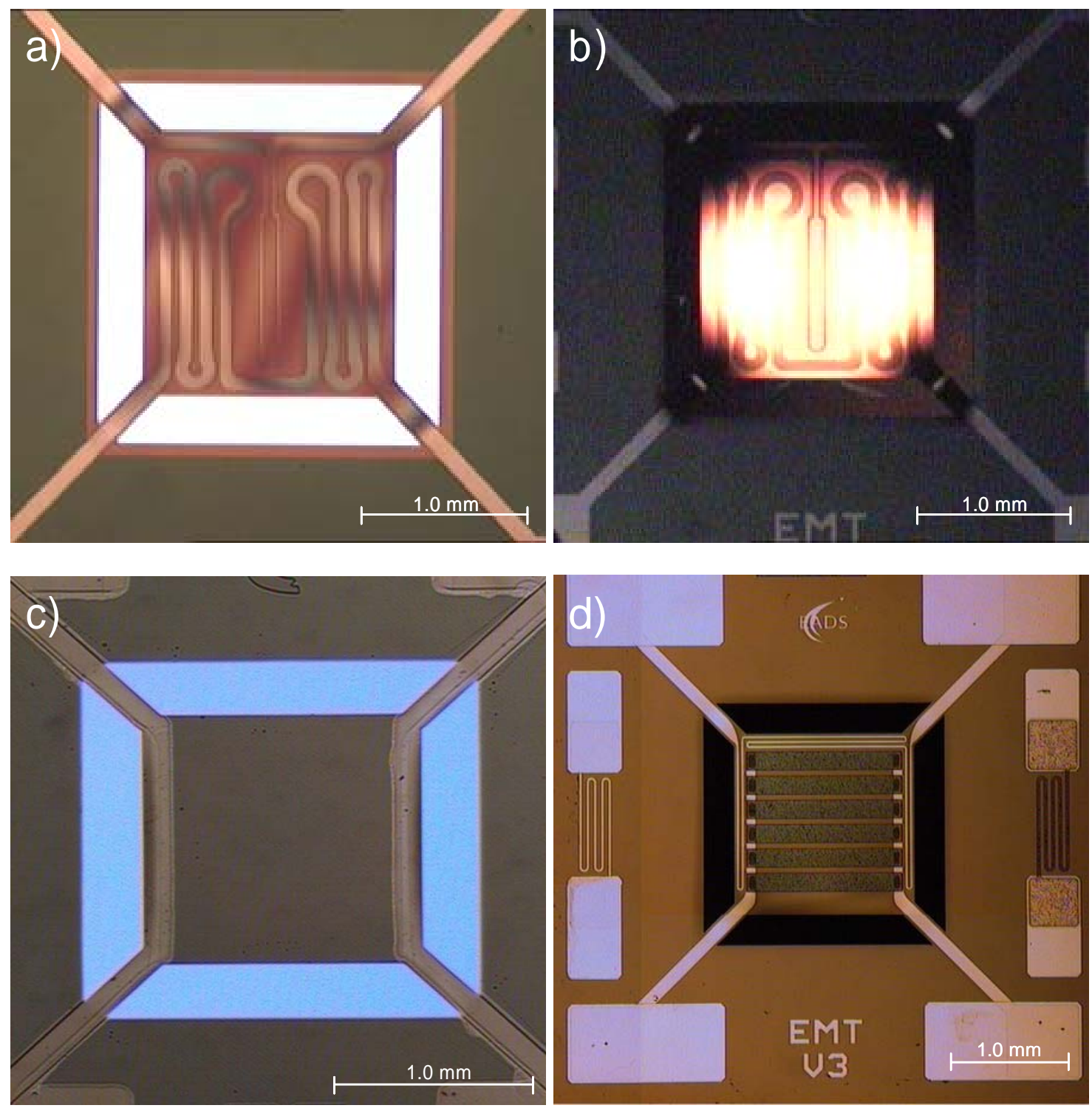

Figure 3. (a) Optical micrographs of the realized micro emitters. The EM1 version features a Pt heater meander and a membrane temperature sensor; (b) shows an EM1 emitter operating at $1120 \mathrm{~K}$; (c) EM2 emitter employing the heavily doped Si (Si:B) layer as a bulk heater material. Contacting of the Si:B layer was accomplished by evaporated Pt bridges on the left and right-hand sides; (d) EM3 emitter featuring a semiconducting $\mathrm{SnO}_{2}$ :Sb area heater contacted by Pt metallisations (bright areas).

\section{Results and discussions}

All investigations had been performed on the above-described emitter designs. Measurements were performed to find out the DC heating power consumption and the maximum modulation frequencies of the fabricated emitter designs. With regard to the employed heater materials, detailed measurements had been performed to the end of assessing their long-term performance at high operation temperatures. In these measurements novel heater materials such as platinum silicide (PtSi), degenerately borondoped silicon (Si:B) and heavily n-type doped $\mathrm{SnO}_{2}$ :Sb were compared to the more commonly employed Pt heater metallisation. 


\section{Heating power consumption}

Bearing IR emitter applications in mind, relatively large hotplates were designed with heated areas as large as $1500 \times 1500 \mu \mathrm{m}^{2}$. For this reason our hotplates do not conform to the low power consumption values of our previously designed hotplates where we aimed at gas sensing applications [4]. Instead of the $50-100 \mathrm{~mW}$ power consumption at $700 \mathrm{~K}$ there, the power consumption of our present devices amounts to about $500 \mathrm{~mW}$ at this same temperature. Fig. 4 below shows that the power consumption increases roughly linearly from room temperature $\left(\mathrm{T}_{0} \sim 290 \mathrm{~K}\right)$ up to about $800 \mathrm{~K}$. Thereafter - up to the melting point of the Si support structure - the power consumption increases in a supra-linear fashion with $\left(T-T_{0}\right)$ due to a dominating increase of IR radiation. As indicated in Fig. 4, a temperature calibration of the hotplate devices had been performed by a number of independent techniques. In the first set of measurements, the devices were passively heated on a thermo chuck and the built-in Pt thermometer was used to measure the membrane temperature (triangles); in the second kind of measurement, the devices were actively heated and the melting points of special temperatureindicator crayons (squares) were used to assess the membrane temperature; in the third set of measurement, IR emission spectroscopy (diamonds) was used to estimate the membrane temperature. Results of all tree measurement principles have been included to create the polynomial fit shown as solid line in Fig. 4. The plot exhibits that every measurement method reproduced comparable values of the membrane temperature, consistent with a thermal resistor modelling of the hotplate structures [25].

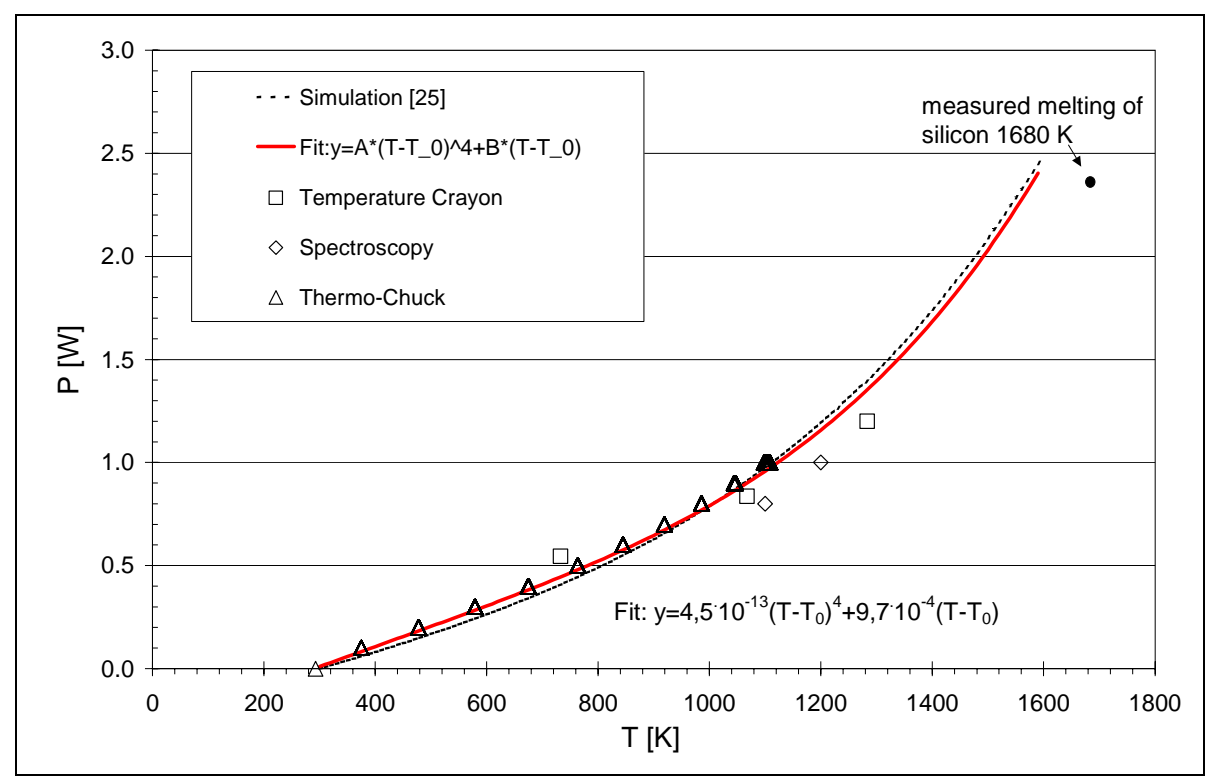

Figure 4. Electrical power consumption as a function of the hotplate temperature for the IR emitter devices shown in Fig. 3. Data points correspond to independent kinds of temperature measurements. The solid (red) and dashed (black) lines stand for a polynomial fit and for the simulation results obtained from a thermal resistor model, described in detail in [25].

\section{Modulation frequency}

The maximum useful operation frequency is determined by the value of the thermal time constant of the IR emitters. This time constant depends on the emitter geometry, on the one hand, and on the heat conductivity and the heat capacity of the hotplate structure, on the other hand. 
As shown in Fig. 5, measurements of the cut-off frequency were performed by measuring the membrane temperature $T_{\text {mem }}$ as a function of the modulation frequency. Devices with two different values of the membrane thickness $(6 \mu \mathrm{m}, 13 \mu \mathrm{m})$ were evaluated. From these measurements a cut-off frequency of $12 \mathrm{~Hz}$ at $70 \%$ modulation depth was revealed.
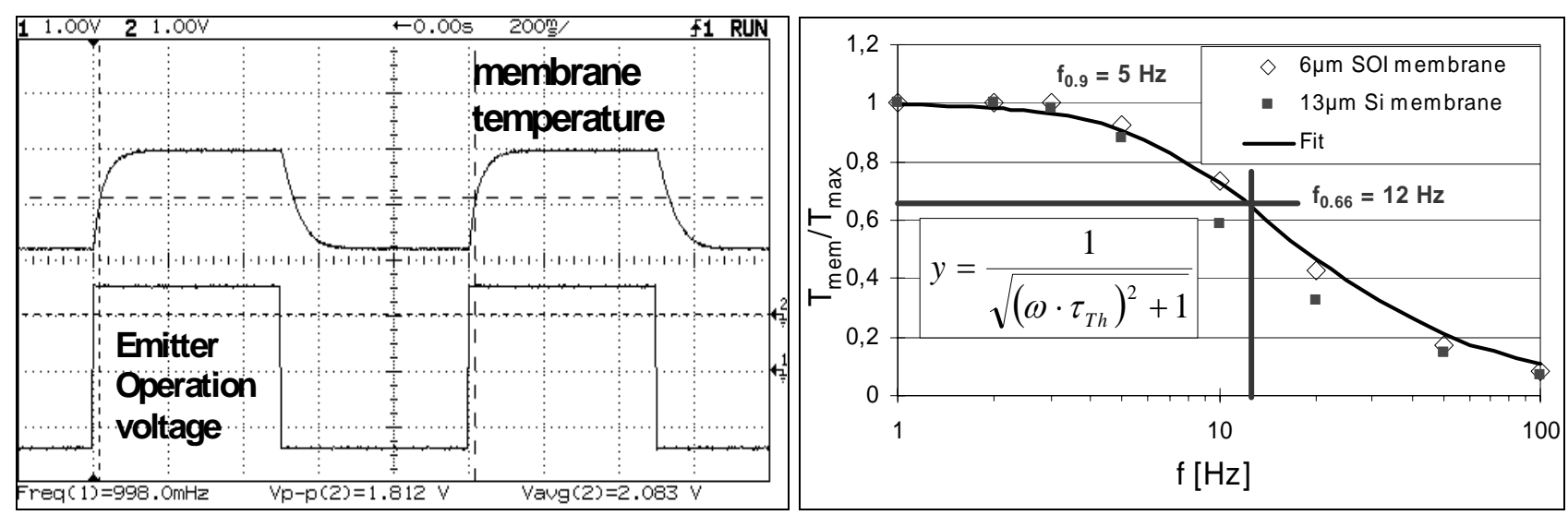

Figure 5. Modulation experiment as performed on an EM1 emitter. (Left) Response of the membrane temperature to $1 \mathrm{~Hz}$ square voltage pulses; (right) membrane temperature as a function of the excitation frequency. Thermal time constants are on the order of $15 \mathrm{~ms}$.

\section{Accelerated degradation tests}

With all kinds of emitters and heater materials, accelerated degradation tests had been performed as illustrated in Fig. 6.

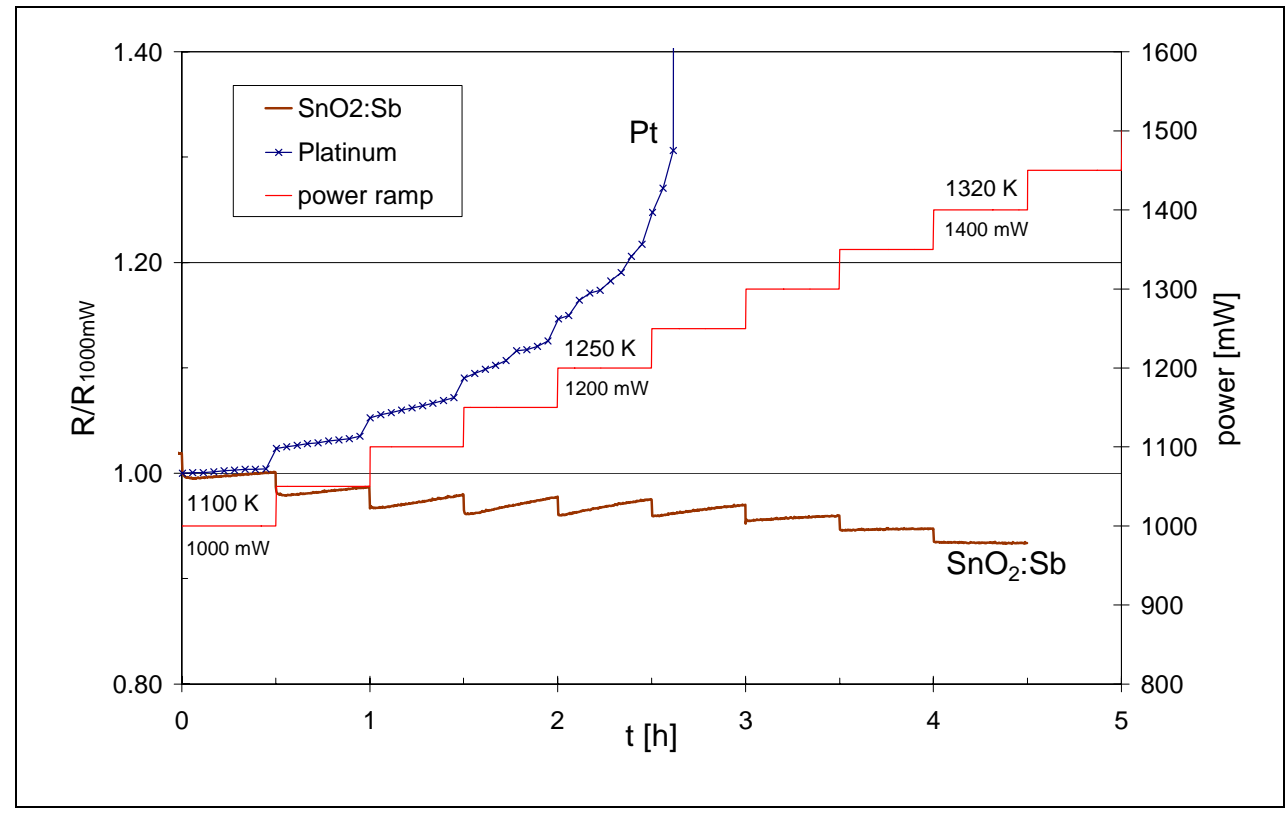

Figure 6. Accelerated aging tests of $\mathrm{Pt}$ (upper curve) and $\mathrm{SnO}_{2}$ : $\mathrm{Sb}$ (lower curve) heater elements in air. Increased temperature (el. input power) leads to a rapidly increasing Pt degradation, whereas $\mathrm{SnO}_{2}: \mathrm{Sb}$ emitters can be operated up to temperatures in the $1300 \mathrm{~K}$ range demonstrating the superior performance of $\mathrm{SnO}_{2}: \mathrm{Sb}$ based heater elements. The seeming instability at lower temperatures is due to adsorption/desorption effects at the $\mathrm{SnO}_{2}:$ Sb surface. 
In these tests the heaters were operated at a constant heater power input, i.e. at a constant membrane temperature for a period of $30 \mathrm{~min}$. Thereafter, the heating power input was increased in $50 \mathrm{~mW}$ steps until the heater finally failed. In the particular test shown in Fig. 6 two EM1 emitters, one metallised with $\mathrm{Pt}$ and the other with $\mathrm{SnO}_{2}$ :Sb, were compared. The data in this figure clearly demonstrate that $\mathrm{Pt}$ heater elements rapidly fail at temperatures above $1100 \mathrm{~K}$, whereas $\mathrm{SnO}_{2}: \mathrm{Sb}$ ones survive up to at least $1300 \mathrm{~K}$.

In Fig. 7 the relative values of the resistance drift of the heater materials at each individual temperature $\mathrm{T}$ are plotted as a function of $1 / \mathrm{T}$. From such Arrhenius plots an activation energy $\mathrm{E}_{\mathrm{a}}$ for the resistance degradation of Pt heaters of about $2.2 \mathrm{eV}$ was obtained. In exactly the same way activation energies for the resistance degradation of PtSi $\left(E_{a} \sim 1 \mathrm{eV}\right)$ and bulk Si:B heaters $\left(\mathrm{E}_{\mathrm{a}} \sim\right.$ $4.3 \mathrm{eV}$ ) were obtained as well. Referring to the high-temperature data of the $\mathrm{SnO}_{2}$ :Sb heater in Fig. 6 it is evident that these latter heaters in principle exhibit very large activation energies. Reliable values, however, could not be extracted from the two highest temperature steps in Fig. 6. The seeming degradation drift of $\mathrm{SnO}_{2}$ :Sb heaters in the lower temperature range is an artefact produced by the residual gas sensitivity of $\mathrm{SnO}_{2}$ :Sb layers. Most likely, these latter resistance changes are due to changes in the $\mathrm{O}^{-}$or $\mathrm{OH}^{-}$adsorbate density and therefore, do not yield any information concerning the bulk degradation rate of the $\mathrm{SnO}_{2}$ :Sb resistors. Keeping in mind that the $\mathrm{SnO}_{2}$ :Sb heaters exhibit an even larger activation energy than Si:B ones, the data of Fig. 7 clearly reveal the superior performance of semiconductor heaters with respect to metallic ones.

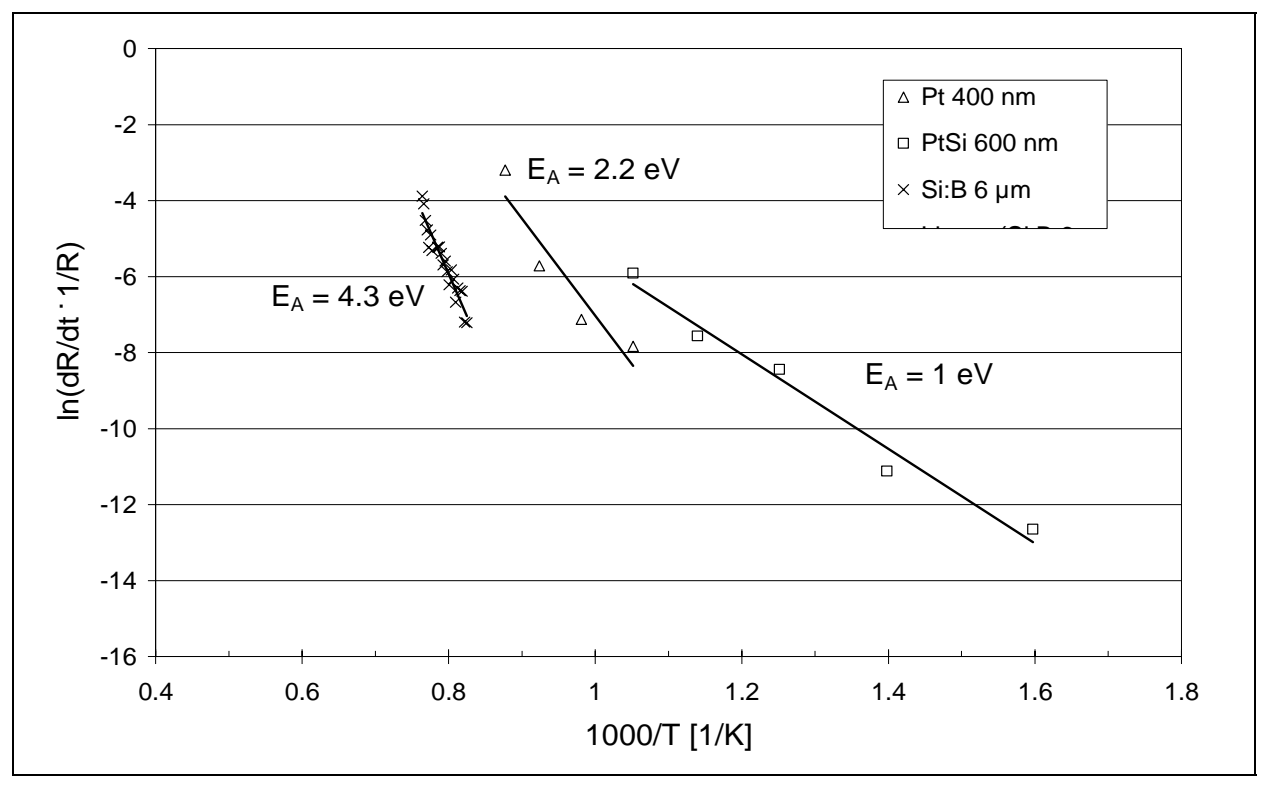

Figure 7. Activation energy for heater degradation for different heater materials. Si:B heaters are seen to perform considerably better at high temperature than metallic ones. $\mathrm{SnO}_{2}$ :Sb heaters exhibited even larger activation energies. Because of a residual gas sensing effect, reliable values of $E_{a}$ could not be obtained in this latter case.

With the activation energies $E_{a}$ obtained, the "low-temperature" lifetime of the different heater materials could be obtained by extrapolation. These latter results are presented in Fig. 8. In this comparison, $\mathrm{SnO}_{2}$ : $\mathrm{Sb}$ heaters were not been taken into account, due to the mentioned uncertainties in determining an activation energy. 


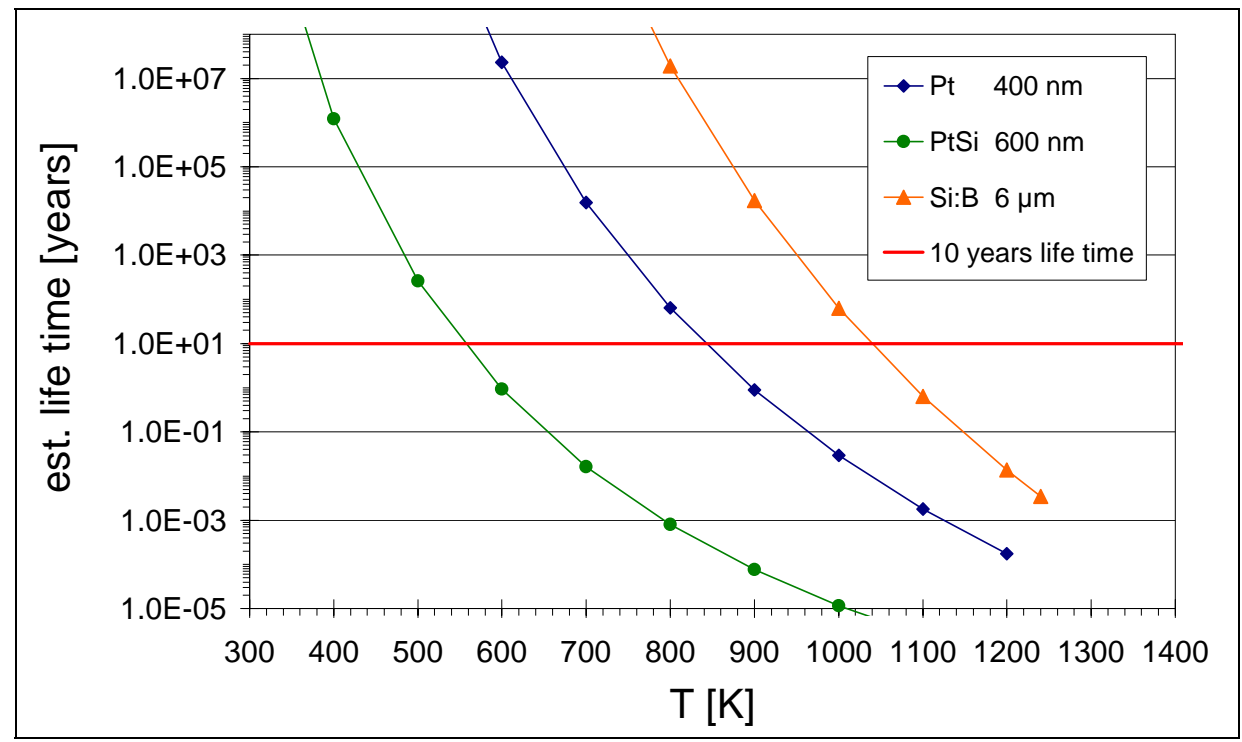

Figure 8. Lifetime estimation for EM1 emitters operated with DC voltage in ambient air. This estimation may be to optimistic as membrane degradation and thermal stress due to the emitter operation (switch on and off) is not taken into account. Nevertheless, 10 years of operation at $1000 \mathrm{~K}$ are considered realistic in the case of Si:B heaters.

According to these data, attaining thermal lifetimes of the order of 10 years needs to limit the maximum operation temperature of PtSi emitters to $550 \mathrm{~K}$, that of Pt emitters to $850 \mathrm{~K}$ and that of Si:B ones to $1050 \mathrm{~K}$.

\section{Direct measurement of the long-term stability of heater metallisations}

Considering the difficulties of extrapolating the $\mathrm{SnO}_{2}$ :Sb heater performance towards commonly employed operation temperatures, direct measurements of the long-term stability of all the above heater materials were initiated. In these latter tests, the emitter devices were heated at about $1100 \mathrm{~K}$ or $1300 \mathrm{~K}$, respectively, for a prolonged period of time to directly assess their long-term stability under typical operation conditions. In this way, a straight-forward assessment of the long-term stability of $\mathrm{SnO}_{2}: \mathrm{Sb}$ heaters was made and the lifetime estimates for Pt, PtSi and Si:B heaters, as obtained from the accelerated degradation tests, could be validated.

Such direct tests again reveal the superior performance of semiconductor with regard to metallic heaters. In the particular experiment shown in Fig. 9 a $\mathrm{SnO}_{2}$ :Sb heater and two Pt heaters were operated at about $1100 \mathrm{~K}$ with constant heating power or alternatively with constant supply voltage. Fig. 9 shows that after one week of testing at $1100 \mathrm{~K}$ the $\mathrm{SnO}_{2}$ :Sb emitter exhibits the same resistivity as in the beginning of the measurement. As the emitter devices were operated in open air, changing air flows caused some noise to become superimposed on the otherwise straight $\mathrm{SnO}_{2}$ :Sb resistivity line. In comparison, the Pt heaters exhibited right from the beginning a large and continuous drift of the heater resistance and finally, failed within 36 hours.

Fig. 10 displays the results of another experiment in which an IR emitter with $\mathrm{SnO}_{2}: \mathrm{Sb}$ heater metallisation was mounted inside a sealed tube filled with ambient air. This kind of housing ensured that the emitter was protected against disturbing influences of changing humidity, air pressure and air 
flow. In this latter experiment, the emitter was permanently operated at a temperature of about $1100 \mathrm{~K}$ for four weeks. Thereafter, its operation temperature was increased to about $1200 \mathrm{~K}$ for another three weeks after which the experiment was interrupted. Fig. 10 vividly shows that no significant degradation of the $\mathrm{SnO}_{2}$ :Sb heater metallisation can be detected during the whole operating period of about seven weeks.

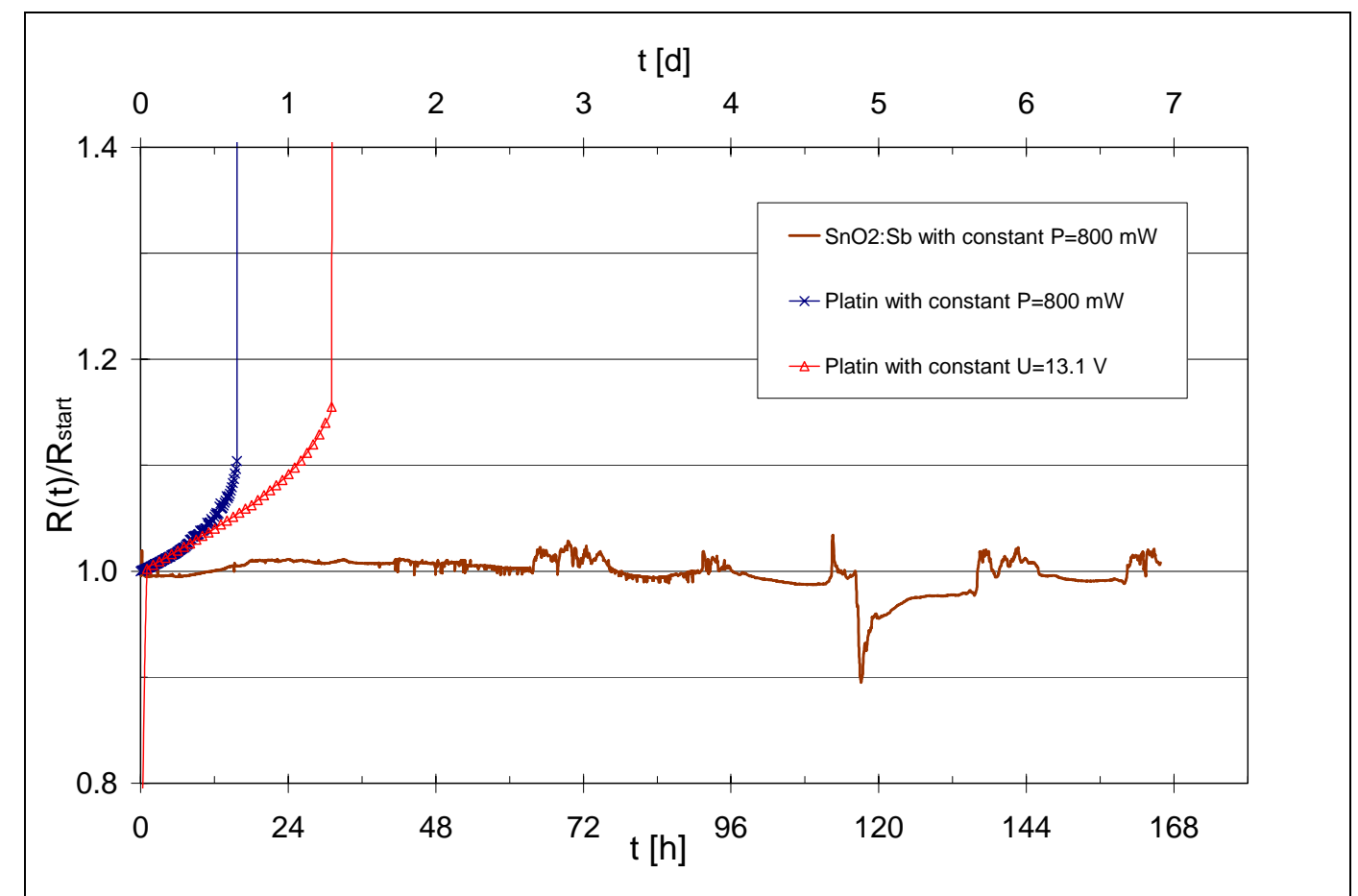

Figure 9. Long-term stability of $\mathrm{SnO}_{2}$ : $\mathrm{Sb}$ based heaters in comparison to $\mathrm{Pt}$ ones. During this experiment, the $\mathrm{SnO}_{2}$ :Sb emitter was unprotected and directly exposed to the ambient atmosphere. The resistivity variations of the $\mathrm{SnO}_{2}$ :Sb emitter are caused by changes in air flow and humidity.

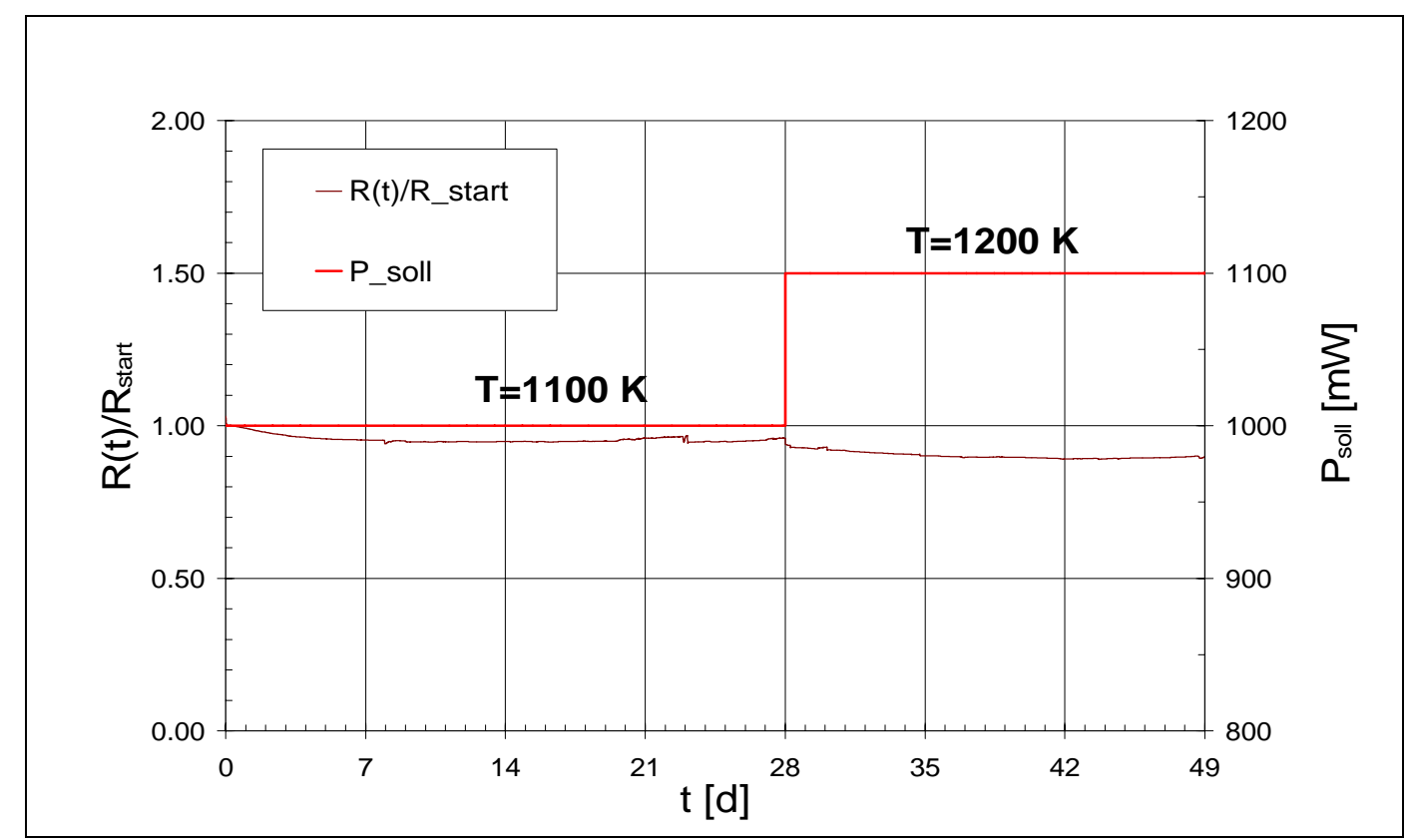

Figure 10. Long-term durability test of heater metallisation based on doped tin oxide. 
In order to obtain more clues on the nature of the degradation phenomena, optical microscopy was performed on degraded heater meanders. Some of these results are shown in Fig. 11. The left-hand panel in this picture shows the state of high-temperature degradation of a Pt heater resistor after 31 hours of operation at a constant temperature of $1100 \mathrm{~K}$. It can be seen that at the hottest points the Pt heater became increasingly porous until it finally failed. This local degeneration can be traced back to electro-migration and inter-diffusion effects both of which are accelerated by high temperature. In contrast, the $\mathrm{SnO}_{2}$ :Sb based heater meander shown in the right panel does not exhibit any visible signs of degradation after operation at $1300 \mathrm{~K}$ for a period of 18 hours. The resistance drift visible in Fig. 10 therefore cannot be attributed to the same kind of degradation as in the Pt case. Very likely the resistance drift in this later case is due to a slow equilibration of the oxygen vacancy density in the semiconductor material [30].
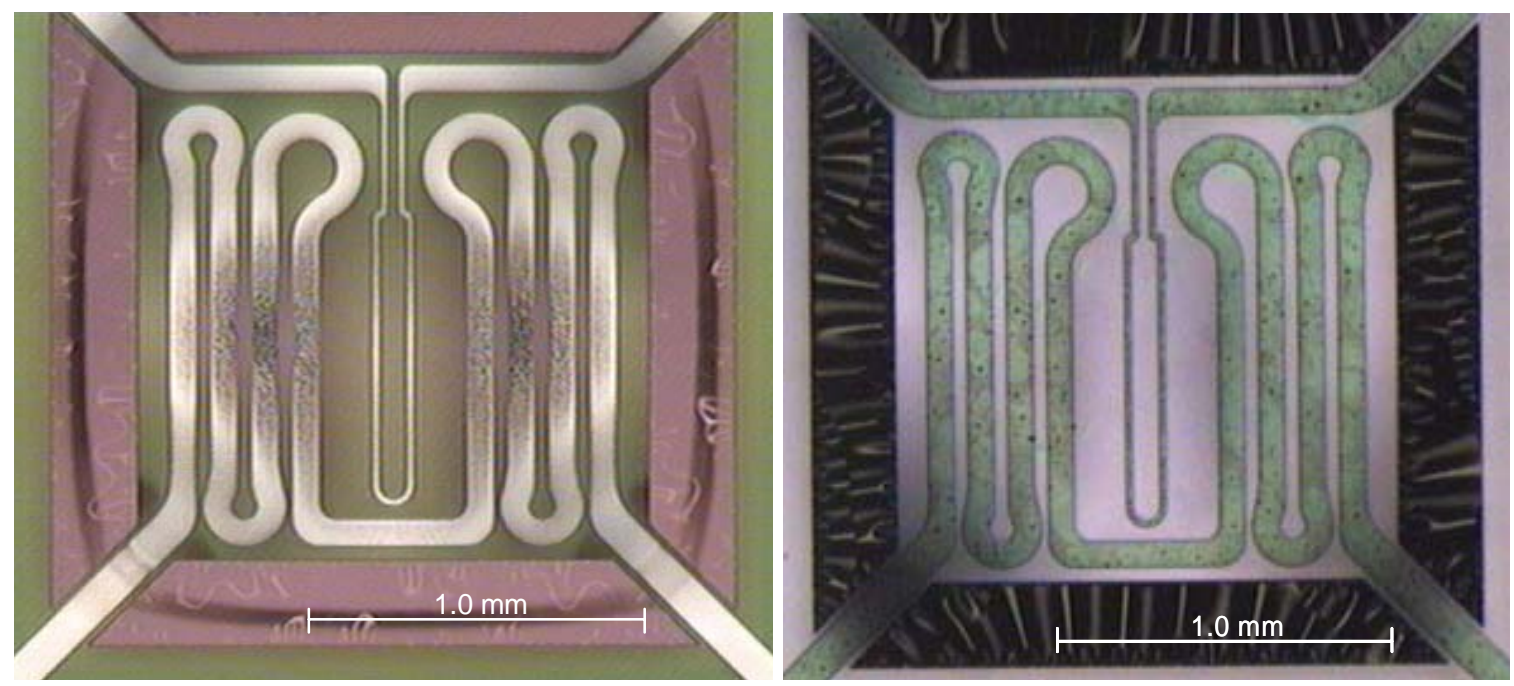

Figure 11. (left) Degradation of a Pt resistor at the two hotpots of an emitter hotplate operating for 31 hours at $1100 \mathrm{~K}$. The metallisation is seen to develop an increasing porosity until resistor failures occur; (right) an $\mathrm{SnO}_{2}$ :Sb based resistor after 18 hours of operation at $1300 \mathrm{~K}$. Here, no significant degradation can be observed.

\section{$\mathrm{SnO}_{2}: \mathrm{Sb}$ based area heater elements}

The above results have clearly shown the superior performance of semiconductor over metallic heater elements and in particular the excellent performance of heater elements based on oxide semiconductors such as $\mathrm{SnO}_{2}$ :Sb. A drawback of this latter material is its relatively high resistivity of about $4500 \mu \mathrm{ohmcm}$ (see Table 1) which is about three orders of magnitude higher than the resistivitity of Pt. As a consequence, operation voltages of about $100 \mathrm{~V}$ were necessary to achieve operation temperatures in the vicinity of about $1300 \mathrm{~K}$ with the EM1 emitter design, which we commonly employed in the case of Pt heater elements.

From an application point of view such high operation voltages are undesirable. In order to attain operation voltages of less than $24 \mathrm{~V}$, the EM3 emitter design was introduced (Fig. 1). In this latter case $\mathrm{SnO}_{2}$ :Sb strips were deposited across the hotplates and low-resistivity Pt contacts on the much colder Si suspensions to provide a low-resistance access to the $\mathrm{SnO}_{2}$ :Sb strips (Fig. 3d). With this design the 
heater resistance could be reduced to about $130 \Omega$, which compares very favourably with the $8 \mathrm{k} \Omega$ heater resistance of the EM1 design in Fig. 3a. At present, investigations are underway to validate the performance of the new emitter design [31].

\section{Conclusions}

High-temperature IR emitter operation could be obtained using SOI-based hotplates as thermally insulated base structures. With all heater materials investigated, high-temperature operation in the range of $1000 \mathrm{~K}$ and above could be obtained. Semiconductor heater materials proved to be clearly superior in performance with regard to metallic ones. Whereas metallic structures failed after several days at high-temperature ( $\mathrm{T} \sim 1000 \mathrm{~K})$, excellent high-temperature stability was obtained with semiconductor heaters such as $\mathrm{Si}: \mathrm{B}$ and $\mathrm{SnO}_{2}: \mathrm{Sb}$. These superior properties are likely to be related to lower current densities in the heater material and lower self-diffusion constants in semiconductor as compared to metallic heater materials. The best results so far have been obtained with the $\mathrm{SnO}_{2}: \mathrm{Sb}$ heater material, which - as an oxide - cannot suffer from any ongoing oxidation during hightemperature operation. The obtained results show clearly that $\mathrm{SnO}_{2}: \mathrm{Sb}$ is a promising material for high temperature heater elements in microsystems. Future applications for such high-temperature MEMS heater platforms are, e.g. flameless ionisation detectors [17] and surface ionisation devices [18]. Both applications rely strongly on a stable, and very constant high temperature heat source with an excellent long-term stability.

\section{Acknowledgments}

The authors whish to acknowledge financial support by the European Union under contract number IST-2001-37802 (NetGas) and by the German Ministry of Education and Research under the contract 16 SV 1532 (IESSICA).

\section{References}

1. Moseley, P.T.; Norris, J; Williams, D.E. Techniques and Mechanisms in Gas Sensing, Adam Hilger, Bristol, Philadelphia and New York, 1991.

2. Wöllenstein, J.; Böttner, H.; Jaegle, M.; Becker, W.J.; Wagner, E. Material properties and the influence of metallic catalysts at the surface of highly dense $\mathrm{SnO}_{2}$ films. Sensors \& Actuators B, 2000, 70, 196.

3. Bârsan, N. Fundamental and practical aspects in the design of nanoscaled $\mathrm{SnO}_{2}$ gas sensors: a status report. Fresenius J. Anal. Chem., 1999, 365, 287.

4. Müller, G.; Friedberger, A.; Kreisl, P.; Ahlers, S.; Schulz, O.; Becker, T. A MEMS toolkit for metal-oxide-based gas sensing systems. Thin Solid Films, 2003, 436, 34.

5. Sberveglieri, G.; Hellmich W.; Müller, G. Silicon hotplates for metal oxide gas sensor elements. Microsystem Technologies, 1997, 3, 183.

6. Heilig, A.; Barsan, N.; Weimar, U.; Göpel, W. Selectivity enhancement of $\mathrm{SnO}_{2}$ gas sensors: simultaneous monitoring of resistances and temperatures. Sensors \& Actuators B, 1999, 58, 30. 
7. Brand, D.; Krauss, A.; van der Schoot, B.; Weimar, U.; Bârsan, N.; Göpel, W.; de Rooij, N.F. Design and fabrication of high-temperature micro-hotplate for drop-coated gas sensors. Sensors \& Actuators B, 2000, 68, 223.

8. Gardner, J.W.; Bartlett, P.N. Electronic noses: Principles and applications, Oxford University Press, 1999.

9. Gardner, J.W.; Lee, S.M.; Bartlett, P.N.; Guerin, S.; Briand, D.; de Rooij, N.F. Silicon planar microcalorimeter employing nanostructured films. Transducers 2001, Germany, Munich, Germany, June 10-14, 2001.

10. Kreisl, P.; Helwig, A.; Müller, G.; Obermeier, E.; Sotier, S. Detection of hydrocarbon species using silicon MOS field-effect transistors operated in a non-stationary temperature-pulse mode. Sensors \& Actuators B, 2005, 106, 442.

11. Lobert, P.E.; Bourgeois, D.; Pampin, R.; Akheyar, A.; Hagelsieb, L.M.; Flandre, D.; Remacle, J. Immobilization of DNA on CMOS compatible materials. Sensors and Actuators B, 2003, 92, 90.

12. Stankova, M.; Ivanov, P.; Llobet, E.; Brezmes, J.; Vilanova, X.; Gràcia, I.; Cané, C.; Hubalek, J.; Malysz K.; Correig, X. Sputtered and screen-printed metal oxide-based integrated micro-sensor arrays for the quantitative analysis of gas mixtures. Sensors and Actuators B, 2004, 103, 23.

13. Solzbacher, F.; Imawan, C.; Steffes, H.; Obermeier, E.; Eickhoff, M. A new SiC/HfB 2 based lowpower gas sensor. Sensors and Actuators B, 2001, 77, 111.

14. Pollien, A.; Baborowski, J.; Ledermann, N.; Muralt, P. New Material for thin film filament of micromachined hot-plate. Transducers 2001, Munich, Germany, June 10-14, 2001.

15. Yuasa, H.; Ohya, S.; Karasawa, S.; Akimoto, K.; Kodato, S.; Takahashi, K. Single crystal silicon micromachined pulsed infrared light source, Transducers 1997, Chicago, June 16-19, 1997.

16. Ohlckers, P.; Ferber, A.M.; Dmitriev, V.K.; Kirpilenko, G. A photo-acoustic gas sensing silicon microsystem. Transducers 2001, Germany, Munich, Germany, June 10-14, 2001.

17. Luthardt, M. Ein flammenloser Ionisationsdetektor, CLB Chemie in Labor und Biotechnik, 48. Jahrgang, Heft 5, 1997.

18. Rasulev, U.Kh.; Nazarov, E.G.; Khudaeva, G.B. Chromatographic determination of trace amounts of amines using surface ionization detector. Journal of Chromatography A, 1995, 704, 473.

19. Krötz, G.; Legner, W.; Müller, G.; Grüninger, E.; Smith, L.; Leese, B.; Jones, A.; Rushworth, S. Structural and electronic characterisation of ß-SiC films on Si grown from monomethylsilane precursors. Materials Science and Engineering, 1995, B29, 154.

20. Eickhoff, M.; Möller, H.; Rapp, M.; Krötz, G. Selective growth of high-quality 3C-SiC using a $\mathrm{SiO}_{2}$ sacrificial-layer technique. Thin Solid Films, 1999, 345, 197.

21. Fehlner, F.P. Low temperature oxidation of metals and semiconductors. J. Electrochem. Soc., 1984, 131(7), 1645.

22. Eickhoff, M. PhD thesis, Technical University of Munich, 1999.

23. Sze, S.M. Physics of semiconductor devices, J. Wiley \& Sons, New York, 1981.

24. Landolt-Börnstein Group III Volume 17a Semiconductors: Physics of Group IV Elements and IIIV Compounds, Springer-Verlag Berlin 1982, ISBN 3-540-10610-3.

25. Schulz, O.; Müller, G.; Lloyd, M.; Ferber, A. Impact of environmental parameters on the emission intensity of micromachined infrared sources. Sensors \& Actuators A, 2005, 121, 172. 
26. Terrier, C.; Chatelon, J.P.; Roger, J.A. Electrical and optical properties of $\mathrm{Sb}: \mathrm{SnO}_{2}$ thin films obtained by the sol-gel method. Thin Solid Films, 1997, 295, 95.

27. Friedberger, A.; Kreisl, P.; Rose, E.; Müller, G.; Kühner, G.; Wöllenstein, J.; Böttner, H. Micromechanical fabrication of robust, low-power metal-oxide gas sensors. Sensors and Actuators B, 2003, 93, 345.

28. Castro, M.S.; Aldao, C.M. Characterization of $\mathrm{SnO}_{2}$-varistors with different additives. Journal of the European Ceramic Society, 1998, 18, 2233.

29. Sahar, M.R.; Hasbullah, M. Properties of $\mathrm{SnO}_{2}$ based ceramics. J. Mat. Sci., 1995, 30, 5304.

30. Grimes, C.A.; Dickey, E.C.; Pishko, M.V. Encyclopedia of Sensors, ISBN 1-58883-056-X.

(C) 2006 by MDPI (http://www.mdpi.org). Reproduction is permitted for non-commercial purposes. 